Revista de la red interuniversitaria de estudios sobre las literaturas rioplatenses contemporáneas en Francia

$21 \mid 2020$

Glosolalias transplatinas: fantasmas, utopías y

ficciones lingüísticas

\title{
La podrelengua de Girondo
}

La pourrilangue de Girondo

The Putrilanguage of Girondo

Raúl Antelo

\section{(2) OpenEdition}

\section{Journals}

Electronic version

URL: http://journals.openedition.org/lirico/9703

DOI: $10.4000 /$ lirico.9703

ISSN: 2262-8339

Publisher

Réseau interuniversitaire d'étude des littératures contemporaines du Río de la Plata

Electronic reference

Raúl Antelo, «La podrelengua de Girondo», Cuadernos LIRICO [En línea], 21 | 2020, Publicado el 12 julio 2020, consultado el 29 enero 2021. URL: http://journals.openedition.org/lirico/9703 ; DOI: https:// doi.org/10.4000/lirico.9703

This text was automatically generated on 29 January 2021.

\section{c) (1) $(9$}

Cuadernos LIRICO está distribuido bajo una Licencia Creative Commons Atribución-NoComercialSinDerivar 4.0 Internacional. 


\title{
La podrelengua de Girondo
}

\author{
La pourrilangue de Girondo \\ The Putrilanguage of Girondo
}

\section{Raúl Antelo}

Si las sociedades se mantienen y viven, es decir, si los poderes no son en ellas "absolutamente absolutos", es porque, tras todas las aceptaciones y las coerciones, más allá de las amenazas, de las violencias y de las persuasiones, cabe la posibilidad de ese movimiento en el que la vida ya no se canjea, en el que los poderes no pueden ya nada y en el que, ante las horcas y las ametralladoras, los hombres se sublevan

(Foucault 1999: 203).

La muerte es el gasto total: horroriza a aquel al que abandona al frío. En ella se expresa la tristeza

del invierno de la Tierra helada. Una muerte humana es lo que pide la Tierra moribunda. El planeta ha dejado de irradiar su fuerza: la ruina de su superficie es señal de agotamiento. Cuando esta superficie, durante el invierno, se aparta del sol, todo se encoge y cualquier gasto se marchita. Sólo la primavera vuelve a traer la fuerza solar: la

vida marchita se descompone con violencia, la planta se embriaga de abono y de luz. La miseria del planeta se interrumpe por un tiempo: la vida

floreciente sonríe entonces al azul del cielo. En cada flor una vegetación loca se vuelve solar: aquello para lo que la Tierra ya no tiene fuerza, la flor lo lleva a cabo como un Sol ebrio de llamas, resplandece y prodiga sin cuento sus vanas 
riquezas. Sin embargo, sólo alcanza su plenitud y rutila para acabar muriendo. La generosa primavera muere igual que el avaro invierno. Pero sus respectivas muertes no detienen su triunfo (Bataille 2005: 101).

1 La sublevada podrelengua, más que final, de la escritura de Oliverio se debate, en sus muchas especies de multillamas faces, porque Girondo expía en su texto viejas jergas carcomidas por los vocablos hipócritas del escenario colonial. Hay de hecho cuatro mil lenguas oscuras en la fiesta de Dakar, mientras la multitud en Tánger arroja y abaraja vocablos, cual clavas, negociando en todas las lenguas de Babel. Pero al idioma nuevo de los argentinos, Oliverio busca darle en cambio con la proa y las olas de una lengua mezclada, para abatirse con furias, reflujos y mareas, que golpean al todo cráter cosmos, sin cráter, sin carácter, de la nada. Cansado, ahonda en los remimos y recaricias del lenguaje, con sus regastados páramos rejugados y reconjugaciones y recópulas, sus remuertas reglas y necrópolis de reputrefactas palabras. Por eso me interesa en especial ver cómo construye Girondo, como ese recurso glosolálico, el escenario de la mierda. En efecto, la mierda, lo Real.

2 Si exceptuamos aquel poema de Espantapájaros en que se confiesa inhábil para conciliar la explosión de fuerzas encontradas que se destruyen mutuamente en él, a tal punto que, antes de cometer el acto más trivial, prefiere, a lo Bartleby, renunciar a cualquier cosa y mandarlo todo a la mierda, esa palabra, mierda, no aparece en sus poemas. Eso indicaría, según Deleuze, el derrumbe del hombre veraz y la aparición del hombre original, el de las excrecreencias. Hay, por ello, un conjunto de textos que Girondo abandonó en una carpeta titulada Diario de un loco de verano escrito en pleno invierno que merecen atención. Allí surge la tristeza del invierno helado del hombre original, el que pasa de la dura y antigua filosofía (que como la felicidad, la fecundidad y la fortuna se condensó en una piedra) a la débil filantropía y de ella, un paso apenas, a la misantropía. Las dos primeras piezas enunciadas por el hombre original son conocidas. "Loco de verano" fue editada por Gastón Gallo en La diligencia y otras páginas (2004). El segundo poema, "Casos locuras interesantes", fue incluido por Daniel Freidemberg en Noche tótem (2000). Ambas versiones conservan entretanto algunas diferencias importantes con la lectura que he podido realizar de los manuscritos no fechados, razón por la cual transcribo a continuación esos dos poemas.

\section{Los textos}

3 Cabe decir, inicialmente, que en el interior de esa carpeta consultada, el Diario de un loco de verano escrito en pleno invierno, hay una portada, con un número 20 al pie derecho, a la que faltan los 19 antecedentes, y que trae la exclamación "Muy corregido!" subrayada, y en su secuencia, leemos:

Loco de verano

Que no pueda fiarse ni de su sombra!

Es comprensible-hasta cierto punto-que al salir a calle los vecinos aprovechen para

llenarnos el departamento de cadáveres y de alfileres de gancho.

Que uno no pueda fiarse ni de su sombra!

Que no pueda uno fiarse ni de su sombra!... 
Ya sé que uno no debe fiarse en la cordialidad, pero de allí a [tachado "uno"] no poder salir a la calle sin que todo el mundo se nos abalance como perros hambrientos y nos muerda los bajos del occipucio [oxsipucio]!

Yo soy el primer convencido que [tachado "no hay que"] es necesario tomar ciertas precauciones con los vecinos pero no exageran un poco cuando al menor descuido me llenan la casa de cadáveres, de tachos de basura y alfileres de gancho.

Yo seré tan susceptible como se quiera pero me parece que uno tiene cierto derecho a quejarse de cuando sin razón le cortan la cabeza [tachado "y uno pregunta"], lo encierran en un cuarto porque uno pregunta dónde está.

Es injusto - ¡qué diablos! - que mis enemigos hayan inventado un instrumento con el cual se entretienen en llenarme la casa de inmundicias y me gritan [a cada instante] desde todos los puntos de la tierra ¿Quieres basura? Pues que la rumiaremos hasta que se te tape la garganta.

Ya sé que no debemos esperar mucho de nuestros semejantes, que no hay que fiarse demasiado en su cordialidad, pero es una exigencia absurda el pretender pararse de vez en cuando sin que los transeúntes se abalancen sobre nosotros y nos muerdan la espalda y los bajos del occipucio? conservado por la familia, aunque la versión a la que tuve acceso es de hojas sueltas, por lo cual no descarto que, en función de ese trabajo "muy corregido", haya otra versión o versiones. En esta no obstante se lee en lo alto "Casos locuras interesantes", sin la barra intermedia de la edición Colihue, que, más que título, parece ser una simple descripción de hipótesis a seguir desarrollando. Están numeradas, de 1 a 16, y es donde la abyección coprológica surge con más fuerza. Transcribo:

1. El tipo que muerde a todo el mundo, pero que tiene un excelente carácter.

2. Exigir el título de propiedad de todos los crímenes.

3. El que tiene miedo de todo.

4. El que cree que todo el mundo lo caga encima y que le llenan de caca la cama, los armarios, los cajones del escritorio, la casa entera.

5. El que busca su propia cabeza y le pregunta por ella a los vigilantes que acaban de cortársela.

6. El que encuentra cadáveres en todas partes y le llenan la casa de cadáveres.

7. El que los alimentos se le reconstituyen adentro y termina por tener en el estómago una cantidad de animales, de frutales, de legumbres.

8. El que sabe que tiene que explotar y teme explotar a cada rato y pasan los días y los días y no explota nunca.

9. El que cambia de sexo.

10. El que desea revelarlo todo: las montañas, los valles, las conciencias.

11. El que oye voces y sabe que le levantarán una estatua en que se servirán de su fisonomía para simbolizar la libertad y no puede soportar ese destino.

12. El que le revienta que dios le hable con una voz de conciencia.

13. El que está convencido de que sus enemigos han inventado un aparato eléctrico para sepultarlo entre la mierda y oye que le gritan a cada instante: ¿Amas la mierda? Pues te la daremos hasta por la garganta.

14. La petulante que hace un elogio y termina diciendo: En fin, tengo un culo de mármol incrustado de perlas y topacios.

15. Se hace lo que se puede. Cada uno tiene sus manías. ¡Qué diablos! A usted mi coronel ¿le gusta que lo crean caballo? ¡Admirable! A [mí], en cambio, me agrada sublimizar, - y esto por la simple razón, de que yo mismo soy sublime. De ahí que sublimice lo que veo: las chimeneas, las naranjas, las estatuas ecuestres, el universo entero. De ahí que me haga unos órganos sublimes, que me acueste con mujeres sublimes, y que produzca hijos sublimes de dos metros cincuenta y que han perdido la cabeza. 
16. Como tengo una columna vertebral [tachado "que"] tan elástica, que puede transportarme a la altura que desee, no necesito subir al Aconcagua para [tachado "saber"] conocer la importancia de los humanos.

Quisiera detenerme en las dos últimas locuras interesantes. Tras la resignación popular ("se hace lo que se puede"), leo el "cada uno tiene sus manías" como la admisión de una multitud de suplicantes cargando a sus espaldas el mundo, verdaderos Atlas que transportan sus quimeras y nos muestran el lazo irreductible, no solo de los movimientos del pensamiento, sino también los de la imaginación y el deseo. La frase condensa la situación que previamente abordara Baudelaire en uno de sus poemas en prosa que aquí recuerdo en la versión de un amigo de Oliverio, Enrique Díaz-Canedo:

Cada cual, con su quimera

Bajo un amplio cielo gris, en una vasta llanura polvorienta, sin sendas, ni césped, sin un cardo, sin una ortiga, tropecé con muchos hombres que caminaban encorvados.

Llevaba cada cual, a cuestas, una quimera enorme, tan pesada como un saco de harina o de carbón, o la mochila de un soldado de infantería romana.

Pero el monstruoso animal no era un peso inerte; envolvía y oprimía, por el contrario, al hombre, con sus músculos elásticos y poderosos; prendíase con sus dos vastas garras al pecho de su montura, y su cabeza fabulosa dominaba la frente del hombre, como uno de aquellos cascos horribles con que los guerreros antiguos pretendían aumentar el terror de sus enemigos.

Interrogué a uno de aquellos hombres preguntándole adónde iban de aquel modo. Me contestó que ni él ni los demás lo sabían; pero que, sin duda, iban a alguna parte, ya que les impulsaba una necesidad invencible de andar.

Observación curiosa: ninguno de aquellos viajeros parecía irritado contra el furioso animal, colgado de su cuello y pegado a su espalda; hubiérase dicho que lo consideraban como parte de sí mismos. Tantos rostros fatigados y serios, ninguna desesperación mostraban; bajo la capa esplinética del cielo, hundidos los pies en el polvo de un suelo tan desolado como el cielo mismo, caminaban con la faz resignada de los condenados a esperar siempre.

Y el cortejo pasó junto a mí, y se hundió en la atmósfera del horizonte, por el lugar donde la superficie redondeada del planeta se esquiva a la curiosidad del mirar humano.

Me obstiné unos instantes en querer penetrar el misterio; mas pronto la irresistible indiferencia se dejó caer sobre mí, y me quedé más profundamente agobiado que los otros con sus abrumadoras quimeras. (1968: 18-19)

6 Aunque a la deriva, esas sombrías figuras, escritas en pleno invierno (cuando, como nos decía Bataille, la tristeza del mundo anuncia la muerte, el gasto total) increpan no obstante a un coronel ("A usted mi coronel ¿le gusta que lo crean caballo?"). Todo caballo sucumbe a las necesidades humanas, nos enseñó también Bataille, aunque mantiene en la esfera del cálculo cualquier deterioro del principio ontológico, que no es nada más que desencadenamiento. ¿Quién es el coronel? ¿Es un militar genérico al que se dirige esa voz o el poema traduce el cansancio ante el desastre posterior al año 43 ? Aunque ya no se trata de la irresponsable confusión entre un coronel y un termómetro de Espántapájaros, no está claro ${ }^{1}$. Tampoco sería muy ilustrativo saberlo, si recordamos el consejo de Goya en sus Caprichos: "es suponer demasiada ignorancia en las bellas artes advertir al público que en ninguna de las composiciones que forman esta colección se ha propuesto el autor, para ridiculizar los defectos particulares a uno y otro individuo: que sería estrechar demasiado los límites al talento y equivocar los medios de que se valen las artes de imitación para producir obras perfectas" (Beruete y Moret, 1928: 36-7). Pero está clara la salida: Oliverio busca en esos fragmentos una metamorfosis de sublimación. Si antes prefería lo sublimado a lo sublime, el yo lírico se 
piensa ahora a sí mismo como un personaje de estatura ciclópica, un Gulliver pampeano de órganos sublimes, acostándose con hembras sublimes y engendrando hijos no menos sublimes, de mucho más de dos metros, que, acéfalos ${ }^{2}$, han perdido la cabeza. Sometiendo la previsibilidad al prodigio, ese inusitado sujeto poético es portador de masmédula, una columna vertebral tan elástica, que puede transportarlo a la altura que quiera, sin tener que subir al Aconcagua para saber de lo humano y así cuestionar el poder de la vida para generar el orden. Quien así habla y disocia reproducción de repetición es lo viviente mismo de valor negativo, la excepción, la transgresión de la regla. Su lenguaje falsifica pues por la vía de la imaginación la normalidad de los intercambios, aún siendo consciente de que los organismos solo consiguen excentricidades de estructura en el breve instante en que se inicia su desarrollo. Nunca como en ese momento, en que la Argentina monstruosamente se agranda en la misma medida en que se liliputiza, cabe la ponderación de un maestro de Foucault, Georges Canguilhem, para quien la vida no transgrede ni sus leyes ni sus planes estructurales. Los accidentes no son excepciones, y nada hay de monstruoso en las monstruosidades. Como ya había mostrado Bataille en un artículo de 1930, "Los descartes de la naturaleza", si bien no hay en esta excepciones, cuando se piensa el mundo como un sistema de leyes, no es menos cierto pensar que esa máxima ignora que su sentido concreto se lo otorga su relación con el significado de una máxima opuesta, que la ciencia excluye, pero que la imaginación aplica. Esa idea genera el anticosmos, el caos de las excepciones sin leyes. "Este antimundo, cuando es contemplado desde el ángulo de quienes lo frecuentan después de haberlo creado, creyendo todo excepcionalmente posible -olvidando a la vez que sólo las leyes permiten las excepciones-, este antimundo es el mundo imaginario, vértigo y desorden de lo monstruoso" (Canguilhem 1962: 47).

\section{El examen de Goya}

¡La "Olimpia” de Manet está enferma de “mal de

Pott"!

¡Necesita aire de mar!... ¡Urge que Goya la

examine!...

(Girondo 1999: 63) ${ }^{3}$

7 A partir de una exposición realizada en el museo del Prado, inmediatamente después de la guerra, prologada por texto de André Malraux, Georges Bataille nos dice que Goya no es solamente uno de los grandes pintores existentes, ni es solamente el primero en anunciar lo que llamamos la pintura moderna, sino, más aún, es quien pioneramente explora todo el desgarramiento del mundo actual, el vértigo y desorden de lo monstruoso.

$\mathrm{Su}$ historia sólo pertenece en segundo lugar a la del arte: se trata incluso de un momento decisivo - Goya es prácticamente contemporáneo de Sade - en la historia de la individualidad. Las mentes aisladas que se impusieron hasta la época de este hombre entraban al menos en una continuidad de la conciencia social. Los más rebeldes no se inscribían dentro de la humanidad viva como extraños: la subversión, el acuerdo con lo imposible, no habían llevado aún hasta la ruptura moral la desintegración del individuo. $\mathrm{O}$ aquello se hizo en silencio, y el silencio no era comunicable (Bataille1988: 309). 
La idea sería luego desarrollada por Blanchot en Lautréamont y Sade (1949) o por el mismo Bataille, en Las lágrimas de Eros (1961). Mucho más tarde, en diálogo con Yves Bonnefoy, Jean Starobinski observaría también que los cielos sanguíneos de Goya muestran la misma nada que Tiepolo triunfalmente exhibía como libertad galopante pero que, en Goya, siempre atraído por la caída, era substituida por una nada de opresivo cansancio (Bonnefoy 2004: 28), aun cuando de innegable transgresión. Girondo, pensando en la amistad del hombre y la bestia, ya decía en 1924 que Goya grababa como si "entrara a matar"; por ello cabe pensar la escena de guerra del loco de invierno dominada por el poeta-Atlas, como una réplica de lo que el mismo artista español plasmó en algunos de sus cuadros. Quedémonos con la descripción de Romero Brest:

Tanto en el cielo magníficamente límpido y transparente en su entonación grisáceo negruzca de Escena de combate, como en el cielo incendiado - llamas rojas y blancas de Incendio de un hospital, o en el estremecido cielo lluvioso de El huracán, se advierte esa calidad propia de los grises de Goya, al mismo tiempo diáfanos y brillantes. La misma riqueza, con empaste más grueso, se observa en las dinámicas figuras de las tres telas, donde los grises alternan con los ocres en brochazos de gran personalidad. La economía de los tonos puros, que saltan aquí y allá, no deja de ser una característica de este pintor en su época de plenitud. Con ser tan hábiles, ni Eugenio Lucas ni Fortuny, goyesco también éste en cierto modo, nunca lograron esa diafanidad de los grises y ocres, ni consiguieron infundir a la materia el vigoroso dinamismo que tipifica a los cuadros de Goya.

También desde su crisis a fines del siglo XVIII, Goya renuncia a toda clase de sombras destinadas a redondear las formas, y busca afanosamente, y con éxito, el claroscuro que corresponde a la factura del color. Para subrayar el dinamismo de las formas utiliza las oposiciones de claroscuro, pero no a la manera de Rembrandt, es decir, hundiendo los objetos en esa atmósfera de contraste, sino manteniendo el valor significativo y táctil de las mismas. Así lograba no sólo una más elevada tensión, sino también una monumentalidad más vigorosa, como apunta Mayer, apelando a menudo "a la exageración, a la acentuación de lo grotesco y de lo fantástico" (1948: 36).

9 Ese primer cuadro de Goya, "Escena de combate", que a mi juicio duplica los fragmentos 15 y 16 de "Casos locuras interesantes", ha sido recientemente analizado por DidiHuberman como ilustración de los levantamientos, condensados en la crispación y el grito ante exhaustos páramos de remuertas reglas y necrópolis verbales ${ }^{4}$. DidiHuberman subraya, en esa "Escena de combate", el gesto de imprecación trágica, situado más allá del llamado al odio o la venganza, ensayado por la potencia del pueblo anónimo, "plus haut, seul sur la colline", en protesta y sublevación ante las fuerzas armadas, que allí avanzan hacia el exterminio. El cuadro lanza así un emancipatorio grito contra, que traduce una energía soberana, la misma que elabora la tensión dialéctica entre las formas patéticas de la muerte impuesta y los signos vectoriales y dinámicos de una vida rehabilitada. No es difícil reconocer en esa lectura la sobrevida de ciertas lecturas bataillanas, como "Los tiempos de la rebelión" (1951) o "El no-saber y la rebelión" (1952). Pero observemos, además, que la podrelengua de ese solitario poeta-Atlas apunta en dirección a una metamorfosis continua que se emparenta con la más consolidada tradición de la literatura satírica, lo cual, en Goya, no descansaba necesariamente en el significado (Goya no es Hogarth), sino en el significante. Así, en el capricho 57, "La filiación", hay una ridícula escena de esponsales, en que la novia tiene el rostro de un animal, lo cual supone además la vulva dentada de su vieja y rugosa cara, que reposa en su regazo. Todo un juego con el significante mono allí se dispara, no 
sólo en el sentido de simio sino de lindo, pero también con el monóculo que alguien levanta al fondo del grabado, la lente para ver con ojos libres, pero también un disparatado mono-culo, una bataillana historia del ojo, lo cual retoma algo que la literatura de la época solía explorar, como cuando se describe una figura trans como "de gatilla tiene el tono cuando más alto se entona; de la cinta abajo es mona, de la cinta arriba es mono" (Stoichita y Coderch 2000: 215)5. Y esta figura cinocéfala nos devuelve al monstruoso poeta-Atlas de Girondo, aislado ante "los consorcios sin sexo que ha parido la usura y que nunca se sacian de fabricar cadáveres" (Girondo 1999: 166), cuyos noes "plurimono noan al morbo", "no démono, no deo, sin son sin sexo", en otras palabras, nos repone ese sujeto enunciado en el noveno tópico de nuestro poema, detentor en fin de la masmédula del lenguaje: "el que cambia de sexo".

¡Ah, la beatitud de vivir en plena sublimidad, y el contento de comprobar que uno mismo es un peatón afrodisíaco, lleno de fuerza, de vitalidad, de seducción; lleno de sentimientos incandescentes, lleno de sexos indeformables; de todos los calibres, de todas las especies: sexos con música, sin desfallecimientos, de percusión! (89).

Recordamos que Georges Bataille veía en Goya al precursor de la pintura moderna y del desgarramiento existencial contemporáneo, alguien que comprendió que lo abyecto se hace en silencio y que el silencio no es comunicable. Bataille radicaliza la lectura de Malraux porque así concluye precisamente su libro sobre Goya: cuando, ya casi ciego, Goya compone su figura del coloso recostado en la montaña, nos remite a una figura previa, Saturno comiendo a sus hijos, y nos permite entonces concluir: "Ensuite commence la peinture moderne" (Malraux 1950: 177-8). De hecho, poco después, en septiembre de 1949, escribiendo sobre Goya y la lucha de clases, el mismo Bataille añadiría que, frente a la acción que conduce a lo imposible, le responde un arte que hace de lo imposible su objeto, con lo cual define a Goya como el pintor mismo de lo imposible, esa noción tan relevante para Blanchot, un artista que se desbordó en sutiles vibraciones de la locura, grisantes para Bataille, o grisáceo negruzcas para Romero Brest.

\section{Lo real que retorna}

11 Pero no desdeñemos el comienzo del análisis de Didi-Huberman: "dans un tableau qui se trouve aujourd'hui au musée national des Beaux-Arts de Buenos Aires, Goya a représenté une scène de massacre proche des Désastres de la guerre". Ese cuadro, que es la "Escena de combate" descripta por Romero Brest, mucho antes de ser colgada en el museo, había pertenecido a Miguel Cané, quien la compró, asesorado por el duque de Alba, en 1886, en su época de embajador argentino en España, junto a otros cuadros, entre ellos Procesión de disciplinantes, encargado por Gabriel Larsen del Castaño; Fiesta popular, comprada por Parmenio T. Piñero, y otros dos cuadros de Goya adquiridos por el Jockey Club de Buenos Aires, La boda y Procesión sorprendida por la lluvia, este último destruido en el incendio del Jockey en 1953 (Corradini 1965). Conocemos las circunstancias del incendio: la muerte por explosivos de varios participantes en una manifestación de la CGT el 15 de abril de 1953 y la represalia a la noche, el incendio de varios locales partidarios, entre ellos, el Jockey, con la Procesión sorprendida por la lluvia de Goya. Es decir, que la "Escena de combate" es el contracampo de esa noche de san Bartolomé: retrata el tiempo que también pinta y lo que era un cuadro sin auténtica temporalidad, manifiesta, deconstruido, una abdicación histórica del arte y su lenguaje. 
12 En su estancia en Madrid, Cané había querido escribir un libro, inconcluso, sobre el arte español, del que nos quedaron sólo algunas páginas. En una de ellas observa que "la vida nacional entera era una oración colosal" (Cané 1919: 51), la lengua de un monstruo $^{6}$. ¿Qué o quién es esa figura? No es ese coloso goyesco alegoría del pueblo español que, miniaturizado al pie, intenta huir. Ni lo es de Napoleón, porque Goya siempre retrató a sus soldados sin afectación y naturalmente. Tzvetan Todorov se inclina por ver en él al espíritu de la guerra que no deja de no representarse. La guerra, esa locura que se escribe siempre en invierno.

Del mismo modo, tal como el eterno combate de Goya, que Girondo no pudo desconocer, los poemas que vengo leyendo nos abren la escena de lo imposible. Alguien en ellos vocifera porque "cree que todo el mundo lo caga encima y que le llenan de caca la cama, los armarios, los cajones del escritorio, la casa entera". Acéfalo, "busca su propia cabeza y le pregunta por ella a los vigilantes que acaban de cortársela". Como leeremos en Perlongher, "encuentra cadáveres en todas partes y le llenan la casa de cadáveres". Ese "Loco de verano" sabe que le "llenan la casa de cadáveres, de tachos de basura y alfileres de gancho". Imposibilitado de practicar la antropofagia ritual, esa que Oliverio impulsó en sus años mozos con el amigo Zapata Quesada (Zapata Quesada 1913), sufre de un impulso antropoemético porque "los alimentos se le reconstituyen adentro y termina por tener en el estómago una cantidad de animales, de frutales, de legumbres". Sabe que no puede, a lo Carlos Argentino Daneri, emprender la obra hegeliana absoluta ("le revienta que dios le hable con una voz de conciencia"), pero también "sabe que tiene que explotar y teme explotar a cada rato y pasan los días y los días y no explota nunca". Por ello se vuelve paranoico ("está convencido de que sus enemigos han inventado un aparato eléctrico para sepultarlo entre la mierda y oye que le gritan a cada instante: ¿Amas la mierda? Pues te la daremos hasta por la garganta”).

En esa escena casi pasoliniana, casi Salò, la mierda aparece en Oliverio ("el tipo que muerde a todo el mundo, pero que tiene un excelente carácter") como antónimo del combate. Es su consecuencia y también su vestigio. La excrecreencia surge cuando transformamos el mundo hasta la médula, hasta la masmédula pero ese cambio, lejos de impulsarnos al desencadenamiento, nos detiene. La potencia que nos transforma no es ya un acto consciente o individual: viene de más lejos y opera libre de cualquier decisión. La podrelengua que la traduce ya no se reconoce en un único rostro y traza para sí un territorio donde todos los tiempos, todos los espacios, quedan suspendidos, aunque pasajeramente conservados. Se diseña así, según Emanuele Coccia (2018 Web), un quiasmo que transforma al mundo en laboratorio genético, en la misma medida en que el sujeto se vuelve un agente de constante transformación, un mordedor serial.

Ya sé que uno no debe fiarse en la cordialidad, pero de allí a no poder salir a la calle sin que todo el mundo se nos abalance como perros hambrientos y nos muerda los bajos del occipucio.

En Van Gogh, el suicidado de la sociedad, Antonin Artaud nos dice que el pintor holandés fue radical en despojarnos (dépouiller), hasta la médula, como quien se despioja ( $s$ 'épouiller) de una obsesión. En 1919, al volver de Buenos Aires, Marcel Duchamp se corta el pelo hasta la raíz. Dibuja con la navaja en la región occipital un cometa con su estrella: Tonsure de 1919 - Paris / Marcel Duchamp ${ }^{7}$. La causa aparente fue una infección de piojos porteños. Pero la estrella occipital, antevista en un manuscrito duchampiano de 1912, es en Oliverio igualmente la mordida del tiempo que retorna. En la colección del Museo d'Orsay hay un modelaje de pérdida del hueso occipital (y por lo tanto de las sensaciones, la memoria) que anticipa los modelajes en cera del Duchamp final. Es 
decir, la metamorfosis de la mímesis en aísthesis. Del mismo modo, en el poema 22 de Espantapájaros, el poeta se imagina como un acumulador, cargado a través del tiempo y del espacio, que no puede resistir al contacto de los cuerpos, de las lenguas. Su carne adquiere, poco a poco, propiedades de imán y todo aquello que le perfora la epidermis, que le practica una tonsura, lo emparenta con esos fetiches africanos acribillados de hierros enmohecidos que Oliverio conoció a través de los libros de Carl Einstein. De a poco, las descargas que ponen a prueba los nervios en alta tensión lo galvanizan, "desde el occipucio hasta las uñas de los pies" y así se escapan multillamas que lo obligan a vivir en pelotas, despojado de todo. No es otro el diseño glosolálico de la podrelengua. Construir esa escena es ofrecer un espacio de lenguaje a todo aquello (gestos y palabras) que nos confinan. Es salir del estado de impotencia. Es una escena de combate.

\section{BIBLIOGRAPHY}

Bataille, Georges, “Goya”, Oeuvres Complètes, vol. 11, Paris, Gallimard, 1988.

---, El límite de lo útil, Madrid, Losada, 2005. Traducción de Manuel Arranz.

Baudelaire, Charles, Pequeños poemas en prosa / Crítica de arte, Madrid, Espasa-Calpe, 1968.

Traducción de Enrique Díaz-Canedo y Manuel Granel

Beruete y Moret, Aureliano, Goya grabador, Madrid, Blass, 1928.

Bonnefoy, Yves, Goya, Baudelaire et la poésie, Genève, La Dogana, 2004.

Brest, Jorge Romero, “Cuatro cuadros de Goya en Buenos Aires”, Ver y Estimar, vol. I, N 4 , julio

1948, Buenos Aires, Cuadernos de Crítica Artística.

Cané, Miguel, “El arte español”, Prosa ligera, Martín García Merou (ed.), Buenos Aires, La cultura argentina, 1919.

Canguilhem, Georges, "La monstruosidad y lo monstruoso", Diógenes, año 9, no 40, octubrediciembre 1962, Buenos Aires, p. 33-47.

Coccia, Emanuele, "Théorie de la métamorphose", 5/11/2018. Web. Consultado el 28 de febrero 2020.

Corradini, Juan, “Cuatro obras de Goya reivindicadas", Boletín del Museo Nacional de Bellas Artes n⿳o 2, junio 1965, Buenos Aires.

Didi-Huberman, Georges, Désirer désobéir. Ce qui nous soulève, 1, Paris, Les Éditions de Minuit, 2019.

Foucault, Michel, “¿Es inútil sublevarse?”, Estética, ética y hermenéutica, Barcelona, Paidós, 1999. Traducción de Angel Gabilondo.

Girondo, Oliverio, “Cuarenta siglos antes de Voronoff”, Plus Ultra, o 94, feb. 1924, Buenos Aires.

---, Obra Completa, Raúl Antelo (ed.), Madrid, ALLCA XX, 1999.

---, Noche Tótem, Daniel Freidemberg (ed.), Buenos Aires, Colihue, 2000. 
---, La diligencia y otras páginas, estudio preliminar Gonzalo Aguilar, Gastón Sebastián Gallo (ed), Buenos Aires, Simurg, 2004.

Malraux, André, Saturne: Essai sur Goya, Paris, Galerie de la Pléiade, 1950.

Stoichita, Victor y Coderch, Anna María, El último carnaval. Un ensayo sobre Goya, Madrid, Siruela, 2000.

Zapata Quesada, René, Un libro saturniano, Buenos Aires, Otero y Cía, 1913.

\section{NOTES}

1. En "El mal de siglo" (1937), Girondo nos dice que: "la preocupación política adquiere, de tal manera, el carácter de una epidemia. En todas partes, a todas horas, en todos los medios, no se habla, no se piensa, no se lee más que de política y únicamente de política. Desde las señoritas más etéreas hasta las señoronas más emperifolladas, son perfectamente capaces de histerismo al discutir el plan quinquenal o el adiestramiento militar infantil, de los que recibieron las primeras noticias junto con la última moda de París." (1999: 342). En "Nuestra actitud ante el desastre" (1940), leemos: "Ensoberbecidas por una mística que se basa en una absurda superioridad racial, o en el advenimiento de un utópico paraíso proletario, las tiranías más despóticas y regresivas privan al ser humano de toda libertad y rebajan la dignidad de la persona hasta obligarla a prosternarse ante la mentira y el terror. Si en vez de las normas morales que nos rigen, y que el hombre ha conquistado penosamente a través de los siglos, nos propusieran otras que las contraviniesen pero que fueran constructivas, ningún espíritu libre se rehusaría a examinarlas con imparcialidad. Las que se pretende imponer poseen, en cambio, un carácter tan negativo, que ni siquiera ofrecen una posibilidad de convivencia entre los individuos y los pueblos. Pues no contentas con convertir al hombre en uno de los múltiples engranajes de la máquina bélica, exaltan las ventajas de la rapiña y de la violencia, o se valen de los pretextos más fútiles para esclavizar a los pueblos por medio de la infiltración artera, del atropello brutal y despiadado." (328).

2. O cinocéfalos, tal como los describe "Cuarenta siglos antes de Voronoff" un texto sin firma publicado en Plus Ultra, que no cuesta atribuir al primer Girondo, suerte de manifiesto de la razón kínica: "La simpática y culta boga que nos han traído los descubrimientos de Lord Carnavón, hace interesante cuanto se refiere a Egipto. He aquí el cinocéfalo, mono de perruna cabeza, que fue adorado por los egipcios al par de numerosos animales. Esta efigie zoolátrica, que se guarda en el Museo Capitolino de Roma, proviene del templo de Isis, diosa de la fecundidad. Todos cuantos buscan una razón práctica a las divinidades egipcias, afirman que, por ejemplo, el cocodrilo era adorado porque entre las primeras aguas de la inundación bienhechora del Nilo venían envueltos ejemplares de ese reptil. Y como, según afirmaba Edgardo Poe, los egipcios lo sabían todo, ¿no hay derecho a lanzar la afirmación de que hubo en Tebas o en Menfis un cirujano benéfico, precursor de Voronoff? Así podría explicarse el porqué se adoraba al cinocéfalo, portador de glándulas rejuvenecedoras como el chimpancé de nuestros días. El agradecimiento de los Faraones, sacerdotes, escribas y millonarios juvenilmente reformados se tradujo en estatuas y oraciones". (1924: 11).

3. Oliverio leyó varios trabajos sobre Goya. Su biblioteca conserva, entre otros, el de Aureliano de Beruete y Moret, Goya, pintor de retratos (Madrid, Blass,1916); el clásico de Paul Lefort, Francisco Goya: étude biographique et critique, suivi de l'essai d'un Catalogue raisonné de son œuvre gravée et lithographiée (París, Henri Loones, 1877), quien mucho había hecho por su canonización en artículos para la Gazette des Beaux-Arts, así como la edición de los Caprichos de Paul Lafond, Nouveaux Caprices de Goya (París, Société de 
Propagation des livres d'Art, 1907). Oliverio no podía desconocer los artículos publicados por su amigo Ramón Gómez de la Serna en la Revista de Occidente, tales como "El gran español Goya" (Madrid, año V, n.. 47, mayo 1927, p. 191-203) o "Concepto de Goya" (nº 58, abril 1928, p. 20-44), preparatorios del libro que crearía un nuevo canon, Goya (Madrid, La Nave, 1928), libro más tarde reeditado por Espasa Calpe en Buenos Aires. Mucho menos habría pasado por alto el artículo que Ramón publica en La Nación, "Goya en Burdeos", en la navidad de 1936, o los de otro amigo suyo, el ya citado Enrique Diez-Canedo, "Ante un gran centenario. La liberación de Goya" (La Nación, Buenos Aires, 14 marzo 1926, p. 7) o "Goya y la pintura moderna" (La Nación, 18 abril 1926, p. 13).

4. En Désirer désobéir. Ce qui nous soulève, Didi-Huberman escribe: "Dans un tableau qui se trouve aujourd'hui au musée national des Beaux-Arts de Buenos Aires, Goya a représenté une scène de massacre proche des Désastres de la guerre. C'est un carnage d'une violence inouïe : le pouvoir (celui des armes) est montré dans sa capacité à tuer toute puissance (en particulier celle d'une femme, à gauche du tableau, qui ouvre grand les bras et qu'on imagine, parce que son visage est réduit à une tache brune, toute entière dans son cri).

Plus haut, seul sur la colline, un être humain - esquissé pour qu'on n'y reconnaisse sans doute pas plus que de l'humain élémentaire - lève les bras. Tout ensemble geste de désespoir devant ce qui se déroule d'atroce en contrebas, geste d'appel à l'aide en direction d'éventuels sauveurs hors-champ et, surtout, geste d'imprécation tragique au-delà - ou au travers - de tout appel à la vengeance. Comme dans le fusillé célèbre du Tres de Mayo qui, lui aussi, levait grand les bras, c'est moins la signification psychologique isolée du personnage qu'il s'agit d'identifier que la direction de sens donnée par le peintre au tableau tout entier: dans de telles scènes, en effet, c'est en quelque sorte la puissance des peuples anonymes qui proteste et se soulève devant le pouvoir des forces armées qui sont venues l'asservir ou la massacrer. Tout cela qu'on retrouvera, sans surprise, dans Guernica où Picasso jette si fort les bras de ses personnages, avec leurs yeux, avec leurs bouches dans un même élan, que les corps, fussent-ils blessés ou terrassés, continueront de crier contre avec une énergie souveraine, dans la constante dialectique entre les formes pathétiques de la mort subie et les signes vectoriels, dynamiques, de la vie resoulevée." (2019 : 500-502).

5. Más que la inspiración bajtiniana, pesa en la hipótesis de lectura la deconstrucción metafísica, ya que Stoichita y Coderch argumentan que los Caprichos de Goya vieron la luz en una farmacia cercana a la Puerta del Sol, en la calle del Desengaño $\mathrm{n}^{\circ} 1$, en febrero de 1799, es decir, en el último carnaval del siglo XVIII. Comenzaba allí otro tiempo, el Gran Siglo, el tiempo que también pinta, como decía Goya, el tiempo pintorpintado, según Bergamín, porque hasta entonces un cuadro de historia, una "escena de combate", por ejemplo, era un cuadro sin historia, sin auténtica temporalidad, una abdicación histórica del arte y su lenguaje.

6. Goya, Francisco de, El coloso (1808-1812), Óleo sobre lienzo, 116 x $105 \mathrm{~cm}$, Museo del Prado. La obra se emparenta con otras de Goya, como Gigante sentado [aguatinta con bruñidor, fechado entre 1800-1818, Boston, Museum of Fine Arts]; Procesión de disciplinantes (1814-1816), Madrid, Real Academia de Bellas Artes de San Fernando; Casa de locos (1814-1816), Madrid, Real Academia de Bellas Artes de San Fernando o Gran coloso dormido. Lápiz litográfico (1824-28). Museo del Hermitage, San Petersburgo.

7. DUCHAMP, Marcel - Tonsure. (Fotografia 8,8 x b7, 8 cm). Colección Arturo Schwarz, Milán. 


\section{ABSTRACTS}

Girondo's desire to fashion a language that would transcend all languages, beyond the reach of tradition and overcome all linguistic and historic nationalisms and ideologies, cannot simply be seen as an aesthetic gesture assumed by an elitist modernist. The crossing between a particularized literary idiolect and polyglottal trends could only be articulated by a strongly politicized pluridialect with a translinguistic as well as transcultural slant. That indissociable imbrication, from inside and/or outside, of the colonial and the national, or authority and subjection, opens to the fullness of an independent, self-authorizing voice.

El deseo de Girondo de modular un lenguaje que trascendiese a todos los lenguajes, más allá de los límites de la tradición, y que doblegase todos los nacionalismos lingüísticos, históricos, e ideologías, no puede ser visto como un gesto estético asumido por un vanguardista de elite. El cruce entre un idiolecto literario específico y tendencias políglotas sólo puede ser modulado por un pluridialecto muy politizado y tendencias políglotas de carácter translingüístico y transcultural. Esa indisociable imbricación, de dentro y/o afuera, de lo colonial y lo nacional, o de autoridad y sujeción, se abre a la plenitud de una voz independiente y legitimada por sí misma.

Le désir de Girondo de moduler un langage qui transcende tous les langages, par-delà les limites de la tradition, et qui dépasse tous les nationalismes linguistiques, historiques et idéologiques, ne peut être vu comme un geste esthétique assumé par un avant-gardiste de l'élite. Le croisement entre un idiolecte littéraire spécifique et des tendances polyglottes ne peut être modulé que par un pluri-dialecte très politisé et par des tendances polyglottes à caractère translinguistique et transculturelles. Cette imbrication indissociable, intérieure et/ou extérieure, du colonial et du national, ou d'autorité et de assujettissement, s'ouvre à la plénitude d'une voix indépendante et légitimée par elle-même.

\section{INDEX}

Mots-clés: transculturation, nationalisme, colonialisme

Palabras claves: transculturación, nacionalismo, colonialismo

Keywords: transculturation, nationalism, colonialism

\section{AUTHOR}

\section{RAÚL ANTELO}

Universidade Federal de Santa Catarina

antelo1950@gmail.com 